\title{
Insulin induced hypoglycaemia: comparison of glucose and glycerol concentrations in plasma and microdialysate from subcutaneous adipose tissue
}

\author{
Ashraf Kamel, Svante Norgren, Bengt Persson, Claude Marcus
}

Department of

Pediatrics and the

Pediatric Endocrine

Research Unit,

Huddinge University

Hospital, Huddinge,

Sweden

A Kamel

S Norgren

C Marcus

Department of

Pediatrics, St Göran's

Hospital, Karolinska

Institute, Stockholm,

Sweden

B Persson

Correspondence to: Dr C Marcus, Pediatric Endocrine Research Unit, B62, Karolinska Institute, Huddinge University Hospital, S-141 86 Huddinge, Sweden email: claude.marcus@ pediat.hs.sll.se

Accepted 24 August 1998

\begin{abstract}
Aims-To investigate the dynamics between plasma and dialysate glucose during hypoglycaemia in children.

Study design-Six children in prepuberty or early puberty were investigated by multiple blood sampling and microdialysis of subcutaneous adipose tissue during a standard arginine-insulin tolerance test. Glucose and glycerol, as an index of lipolysis, were measured in samples from both compartments. Plasma concentrations of insulin and the main counterregulatory hormones were also measured.

Results-Plasma and dialysate glucose concentrations were very similar at baseline and increased in concert after infusion of arginine, probably in response to glucagon release. After insulin injection, glucose in both plasma and dialysate fell in parallel. The subsequent hypoglycaemic stress response induced a rapid rebound in the plasma concentration with a mean (SD) delay in the dialysate of 16 (3) minutes. Plasma glycerol was approximately fivefold lower than in the dialysate and did not fluctuate significantly. Dialysate glycerol decreased with arginine infusion and reached a nadir immediately following insulin administration. Subsequently, the antilipolytic effect of insulin was overcome by the hypoglycaemic stress
\end{abstract}
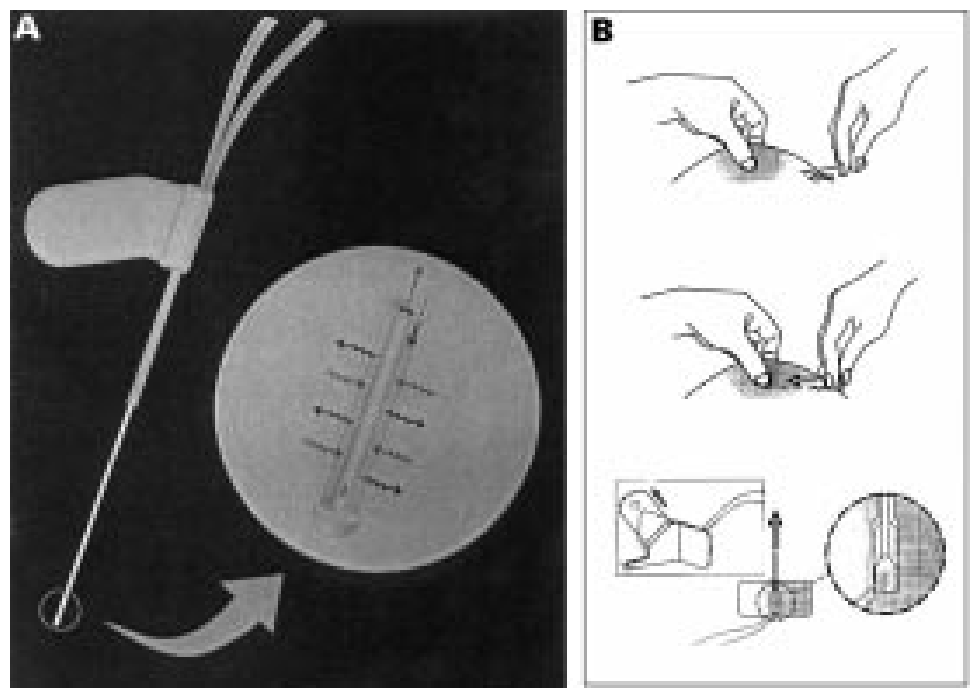

Figure 1 (A) Microdialysis probe. The black arrow indicates the flow of Ringer's solution and the grey arrow the flow of the interstitial fluid. (B) Implantation of the microdialysis probe in subcutaneous adipose tissue. (Top) A needle is used to puncture the skin. (Middle) The introducer is inserted through the puncture hole. (Bottom) The introducer is removed and the device is ready for use. response, and lipolysis prevailed in spite of hyperinsulinaemia.

Conclusion-After rapidly induced hypoglycaemia, rebound of interstitial glucose concentrations is significantly delayed compared with plasma concentrations, and the antilipolytic effect of hyperinsulinaemia is opposed possibly by the hypoglycaemic stress response.

(Arch Dis Child 1999;80:42-45)

Keywords: arginine; insulin; glucose; glycerol; lipolysis; catecholamines; microdialysis; hypoglycaemia

Microdialysis of subcutaneous adipose tissue allows measurement of glucose and lipolysis products and is therefore of potential interest for monitoring patients with brittle glucose homeostasis. ${ }^{1}$ Reliable blood glucose determinations may be difficult to obtain from children and neonates in the lower glucose range, ${ }^{2}$ and blood concentrations of the lipolysis products - that is, glycerol and free fatty acids, during hypoglycaemia are insensitive indicators of lipolysis. Within the normal range of blood glucose concentrations, glucose in the interstitial fluid space of abdominal subcutaneous tissue is almost identical to the blood concentrations. ${ }^{3-5}$ However, we are unaware of any data regarding gradients between plasma and the interstitium glucose in hypoglycaemic children.

Insulin has potent antilipolytic effects in both children and adults, ${ }^{6}$ and the absence of lipolysis products and ketone bodies during episodes of spontaneous hypoglycaemia indicates a hyperinsulinaemic pathogenesis. ${ }^{7}$ Catecholamines are the only hormones with acute and pronounced lipolytic effects after the neonatal period. ${ }^{8}$ When adipocytes are incubated in vitro with insulin and isoprenaline (a $\beta$ adrenergic receptor agonist), insulin drastically reduces the sensitivity for isoprenaline without affecting the maximal lipolytic response. ${ }^{9}$ Recently, this mechanism has been confirmed in vivo in adults, ${ }^{10}$ based on the finding that microdialysis measurements of glycerol reflect changes in lipolysis induced by catecholamines and insulin. ${ }^{11}$

We investigated the hypoglycaemic stress response induced by an arginine-insulin tolerance test (AITT) in children. We aimed to analyse the dynamics between plasma and adipose tissue dialysate glucose concentrations during hypoglycaemia, and the effect of hyperinsulinaemia and counterregulatory hormones on lipolysis in subcutaneous adipose tissue. 
Table 1 Clinical characteristics of the study participants

\begin{tabular}{lllllll}
\hline \multicolumn{7}{l}{ Participant } \\
\cline { 2 - 6 } & $A$ & $B$ & $C$ & $D$ & $E$ & $F$ \\
\hline Age (years) & 11 & 12 & 17 & 13 & 9 & 12 \\
Sex & $\mathrm{M}$ & $\mathrm{M}$ & $\mathrm{M}$ & $\mathrm{M}$ & $\mathrm{F}$ & $\mathrm{F}$ \\
Tanner stage & 1 & 1 & 2 & 1 & 1 & 1 \\
Height (SD) & -3.5 & -2 & -5 & -2 & -3 & -3 \\
Weight (SD) & -1.5 & -1.5 & -4 & -1.5 & -2 & -3 \\
Growth velocity (SD) & -2.5 & -3 & -2.5 & -2.5 & -2.5 & -3 \\
\hline
\end{tabular}

Participant $\mathrm{C}$ was treated with moderate doses $(400-800 \mu \mathrm{g}$ qid) of budesonide and terbutaline inhalations as required.

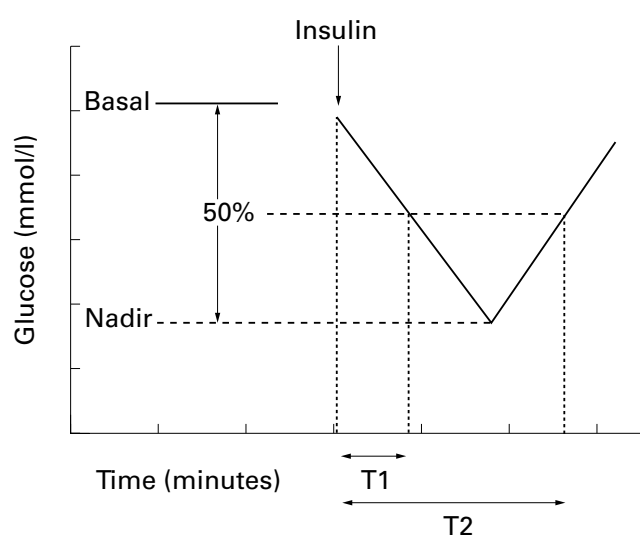

Figure 2 Calculation of the temporal relation between plasma and microdialysate glucose after insulin injection. The time intervals between insulin injection and a $50 \%$ decrease in glucose(T1) and between insulin injection and the subsequent rise to the $50 \%$ level (T2) were calculated from each graph. Basal denotes the glucose concentration before the start of AITT.

\section{Methods}

The study was approved by the ethics committee of the Karolinska Institute, and informed consent was obtained from the guardians and participants.

Six children with short stature in prepuberty or early puberty were included in the study (table 1). The mean (SD) age was 12.3 (1.2) years and all were below -3 SD regarding height for age or had a growth velocity below -2 SD. The children were admitted to the hospital one day before the study.

A microdialysis probe was inserted in the abdominal subcutaneous adipose tissue (fig 1B). Two venous cannulas were placed in the forearms: one for infusion of arginine and insulin, and one for blood sampling. The AITT followed the standard procedure used to study growth hormone $(\mathrm{GH})$ secretion and hypoglycaemic stress response. ${ }^{12}$ After an overnight fast, an intravenous arginine infusion $(0.5 \mathrm{mg} /$ $\mathrm{kg}$ body weight over 30 minutes) was given at
$08: 30$ and insulin $(0.10 \mathrm{U} / \mathrm{kg})$ was given one hour later as an intravenous bolus injection.

The microdialysis device (CMA Microdialysis, Solna, Sweden) has a double lumen plastic cannula equipped with a tubular semipermeable membrane. ${ }^{1}$ Sterile Ringer's solution is continuously pumped through the dialysis tube, where diffusion of molecules along the concentration gradient takes place (fig 1A). The length of the dialysis membrane is $30 \mathrm{~mm}$ and the flow rate is $0.5 \mu 1 / \mathrm{min}$. We have previously found close to $100 \%$ recovery of glucose in children using these conditions. ${ }^{45}$ Microdialysis samples were collected every 15 minutes starting at 0 minutes. All calculations and figures were corrected for a lag phase of 10 minutes between the microdialysis probe and the collecting test tube. Thus, the first microdialysis sample was collected at $0 \mathrm{~min}$ utes and plotted at -10 minutes, and the subsequent sample was collected at 15 minutes and plotted at 5 minutes.

ANALYSES OF HORMONES AND METABOLITES

Blood samples for determination of plasma concentrations of insulin and the counterregulatory hormones glucagon, cortisol, noradrenaline, and GH were drawn at the time points indicated in table 2. Samples for determination of plasma glucose and glycerol were drawn every 15 minutes. GH concentrations were measured by a fluoroimmunometric assay using two monoclonal antibodies. ${ }^{13}$ The concentrations of glucagon, cortisol, and insulin were determined by standard radioimmunoassays. ${ }^{14}{ }^{15}$ Catecholamines were assayed by high performance liquid chromatography. ${ }^{16}$ Plasma and dialysate glucose concentrations were determined by a glucose-oxidase method, ${ }^{17}$ and glycerol concentrations with a glycerol-oxidase method. ${ }^{18}$ To study the temporal relations between changes in plasma and microdialysate glucose concentrations, the intervals between insulin injection and the fall or rise in glucose concentrations were analysed as indicated in fig 2 .

\section{STATISTICS}

Data are presented as mean (SD). After checking for major deviation from normality, the Student's paired $t$ test was used to compare microdialysate and plasma concentrations, and ANOvA was used to assess variations over time in glucose and glycerol concentrations.

Table 2 Plasma hormone concentrations during arginine-insulin tolerance test

\begin{tabular}{rclllll}
\hline $\begin{array}{l}\text { Time } \\
(\mathrm{min})\end{array}$ & $\begin{array}{c}\text { Insulin } \\
(\mathrm{mU} / \mathrm{l})\end{array}$ & $\begin{array}{l}\text { Glucagon } \\
(\text { pmolll) }\end{array}$ & $\begin{array}{l}\text { Cortisol } \\
(\text { nmol/l) }\end{array}$ & $\begin{array}{l}\text { Noradrenaline } \\
(\text { nmolll) }\end{array}$ & $\begin{array}{l}\text { Adrenaline } \\
(\text { nmol/l) }\end{array}$ & $\begin{array}{l}\text { Growth hormone } \\
(\mu \mathrm{g} / \mathrm{l})\end{array}$ \\
\hline-15 & $10(6)$ & - & $372(154)$ & $1.9(1.2)$ & $0.6(0.1)$ & $0.2(0.2)$ \\
0 & $9(4)$ & $1.3(0.4)$ & $285(122)$ & $1.9(0.8)$ & $0.6(0.1)$ & $0.1(0.01)$ \\
15 & $36(15)$ & $3.0(0.7)$ & $264(104)$ & $1.6(0.8)$ & $0.9(0.6)$ & $0.3(0.2)$ \\
30 & $61(21)$ & $1.7(0.8)$ & $283(106)$ & $1.8(0.7)$ & $1.3(1.7)$ & $6.7(3.6)$ \\
60 & $18(10)$ & $1.7(0.4)$ & $383(172)$ & $2.3(0.7)$ & $1.1(0.3)$ & $5.0(2.8)$ \\
75 & $193(200)$ & - & $422(188)$ & $1.4(0.5)$ & $0.9(0.5)$ & $2.7(2.3)$ \\
90 & $71(70)$ & $2.7(0.4)$ & $539(183)$ & $3.9(0.9)$ & $5.1(3.5)$ & $2.2(2.0)$ \\
120 & $32(16)$ & - & $717(141)$ & $1.6(0.01)$ & $1.1(0.3)$ & $2.0(1.0)$ \\
\hline
\end{tabular}

Arginine was infused continuously between 0 and 30 minutes, insulin was given as an intravenous bolus injection at 60 minutes. Data are mean $(\mathrm{SD})$. 


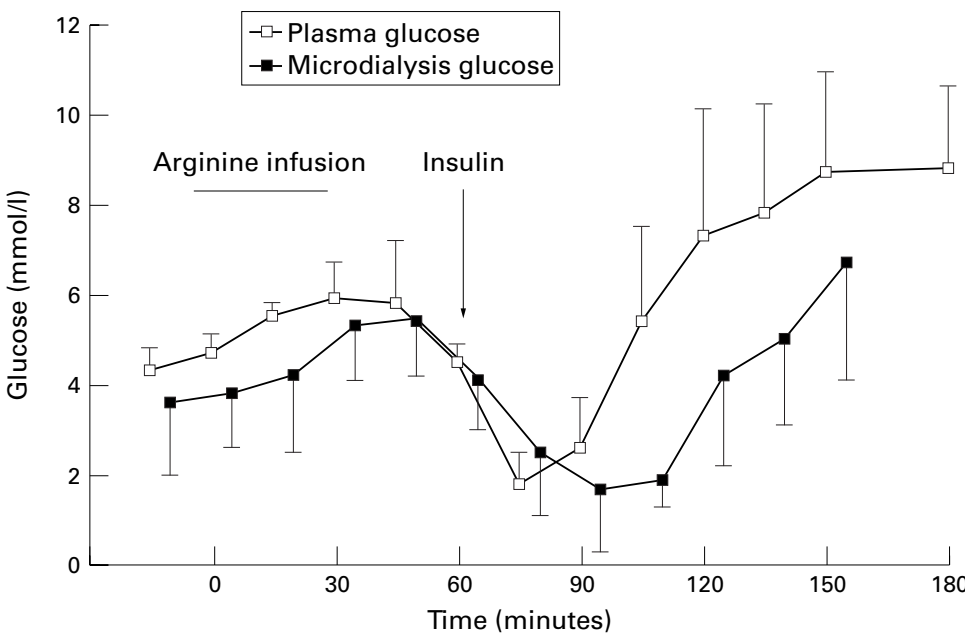

Figure 3 Plasma and dialysate glucose concentrations during AITT. Arginine infusion was given over 30 minutes starting at time 0 . Insulin was given as an intravenous bolus injection at 60 minutes. Data are mean $(S D)(n=6)$.

Table 3 Temporal relation between changes in plasma and microdialysate glucose concentrations

\begin{tabular}{lcl}
\hline & Fall (min) & Rise (min) \\
\hline Dialysate & $10(10)$ & $49(7)$ \\
Plasma & $8(6)$ & $33(8)$ \\
Mean difference & $2(3)$ & $16(3)$ \\
p value & $<0.01$ & \\
\hline
\end{tabular}

The mean interval between the insulin injection and the time points at which the glucose concentration reached a concentration halfway between that at the start of the AITT and the nadir-that is, initially fallen and subsequently risen, was calculated from the individual graphs, $\mathrm{T} 1$ and $\mathrm{T} 2$, respectively (fig 2). Data are mean (SD) except for the mean difference (SE).

\section{Results}

Table 2 shows the endocrine profiles during the AITT. Two of the six participants were partly $\mathrm{GH}$ deficient as defined by peak stimulated plasma $\mathrm{GH}$ concentrations $<10 \mathrm{mg} / \mathrm{l}$. Apart from the diminished $\mathrm{GH}$ response, there was no difference between the $\mathrm{GH}$ deficient and the other children during the AITT.

Before arginine infusion, the mean plasma and dialysate glucose concentrations were very similar (fig 3). In response to arginine infusion, there was a transient increase in plasma glucose $(\mathrm{p}<0.05)$ corresponding to a rapid glucagon

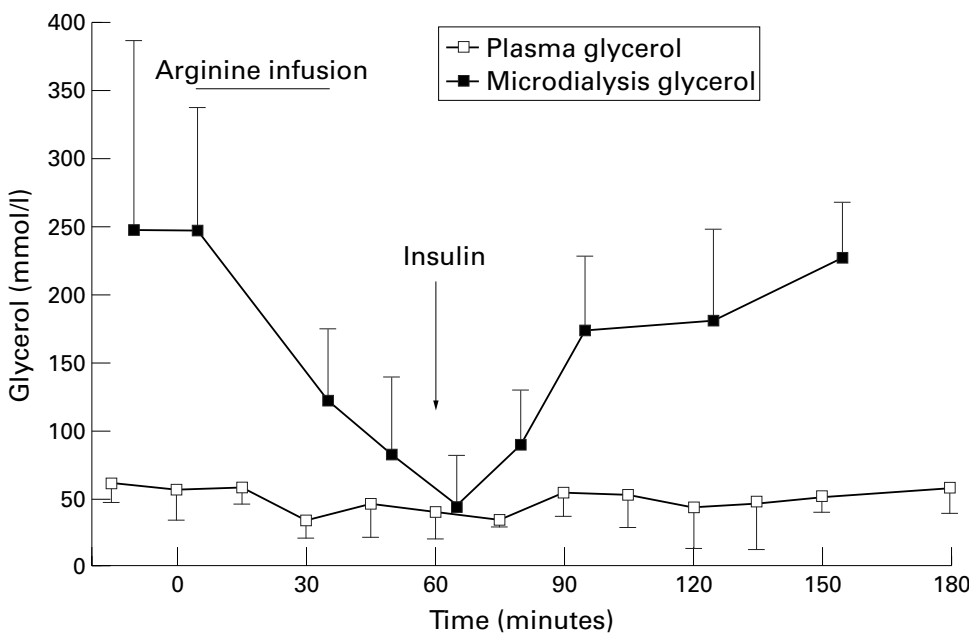

Figure 4 Plasma and dialysate glycerol concentrations during AITT. Arginine infusion was given over 30 minutes starting at time 0. Insulin was given as an intravenous bolus injection at 60 minutes. Data are mean $(S D)(n=6)$. release. The increase in dialysate glucose concentration was not significantly delayed. After the intravenous insulin bolus injection, glucose fell rapidly concomitantly in both compartments. The plasma and dialysate glucose concentrations were very similar, and no delay was observed (fig 3, table 3). Subsequently, plasma glucose concentrations increased rapidly in response to the hypoglycaemic stress. However, the rise in the mean (SD) dialysate glucose was delayed 16 (3) minutes $(p<0.01)$ (table 3$)$. During the remaining time course, the glucose concentrations in the dialysate were significantly lower than in plasma $(\mathrm{p}<0.01)$.

To monitor ongoing lipolysis, glycerol was measured in plasma and dialysate. In plasma, the glycerol concentration was several-fold lower than in dialysate and did not fluctuate significantly during the test (fig 4). In contrast, glycerol concentrations in the dialysate fell rapidly after arginine infusion reflecting inhibition of lipolysis by insulin. Although the subsequent insulin injection further inhibited lipolysis, the dialysate glycerol concentration climbed to the basal concentration 30 minutes after insulin injection $(\mathrm{p}<0.01)$.

\section{Discussion}

Six children were subjected to a rapidly induced hyperinsulinaemic hypoglycaemic episode during an AITT. The hypoglycaemia was most pronounced approximately 30 minutes after insulin injection in both plasma and a microdialysate of subcutaneous adipose tissue, but the ensuing rise in dialysate glucose concentration was delayed compared with plasma. Dialysate glycerol concentrations, reflecting ongoing lipolysis, also reached a nadir following insulin administration, but the antilipolytic effect of insulin was subsequently overcome by the counteracting regulatory hormones.

We cannot estimate the time required for the dialysate glucose concentration to reach the plasma concentration, as the monitoring ended two hours after insulin injection. However, the discrepancy between plasma and dialysate glucose indicates that the adipose tissue glucose concentration does not passively mirror plasma glucose fluctuations - a fact that is important to keep in mind when the microdialysis technique is used to monitor patients at risk for hypoglycaemia. Accordingly, tissue glucopenia may be present even at normal plasma glucose concentrations. Microdialysis does offer an advantage over blood sampling as glucose can be measured continuously for hours or days without blood sampling and consumption. The technique has been used successfully to monitor glucose in neonates with hypoglycaemia ${ }^{4}$ and diabetic patients, ${ }^{19}{ }^{20}$ as well as in neonates ${ }^{5}$ and adults ${ }^{21}$ undergoing surgery. Recently, onsite measurement of glucose by microdialysis for clinical practice became possible in our department. As there is a risk of lower dialysate than blood glucose concentrations, we routinely run a blood glucose determination after determining a low dialysate concentration. 
The mechanism for the delay in the dialysate is not known. The recovery of substances from the extracellular fluid depends on the microdialysis device - that is, the length of the dialysis membrane and the flow rate of the perfusion solution, as well as the microcirculation. ${ }^{1}$ A reduced microcirculation may result in decreased interstitial glucose and increased glycerol concentrations. As local blood flow was not measured in the present study, the potential influence of this factor cannot adequately be evaluated. However, previous data demonstrate that adipose tissue blood flow increases transiently in response to hypoglycaemia. ${ }^{10}$ Thus, the differences in the concentrations of glucose and glycerol between plasma and dialysate can probably not be attributed to altered blood flow. Another possible mechanism is an increased endothelial barrier for glucose during hypoglycaemia as described for insulin. ${ }^{22}{ }^{23}$ Alternatively, hyperinsulinaemia itself may cause differences between dialysate and plasma concentrations. Insulin increases glucose uptake, ${ }^{24}$ whereas glucagon has no local effects in adipose tissue. ${ }^{25}$ In response to increasing insulin concentration, an augmented uptake of glucose may explain the lack of delay in the dialysate during the first half of the test. A delay should otherwise have been expected for the diffusion of glucose from the blood stream. On the other hand, a persistent peripheral glucose uptake induced by insulin, in combination with a slow diffusion of glucose from the blood stream to the interstitial water space, may delay normalisation of the interstitial glucose concentrations.

Interstitial glycerol concentrations decreased profoundly during arginine infusion, probably because of the release of insulin. Despite the further rise in plasma insulin after insulin administration, dialysate glycerol concentration increased. Therefore, it is likely that the catecholamine surge induced by hypoglycaemia counteracted the antilipolytic effect of insulin, confirming previous in vitro ${ }^{9}$ and in vivo data. ${ }^{10}$ As hyperinsulinaemia failed to inhibit lipolysis during hypoglycaemia, the absence of ketone bodies and lipolytic products is not a prerequisite for the diagnosis of insulin induced hypoglycaemia, which has been suggested previously. ${ }^{76} 27$ The situation may be different in early infancy, as during this time the lipolytic effect of catecholamines is weak, secondary to enhanced $\alpha_{2}$ adrenoceptor activity. ${ }^{82-30}$

We thank CMA Microdialysis for assistance with figures of the microdialysis device. The study was supported by grants from the Swedish Medical Research Council (9941 and 11332), Karolinska Institute, Pharmacia Upjohn, the Swedish Diabetes Foundation, the Wera Ekström Foundation, the Samariten Foundation, and the Sven Jerring Foundation.

1 Ungerstedt U. Microdialysis-principles for studies in animals and man. F Intern Med 1991:230:365-73.

2 Elimam A, Horal M, Bergstöm M, Marcus C. Diagnosis of hypoglycemia: effects of blood sample handling and evaluation of a glucose photometer in the low glucose range. Acta Paediatr 1997;86:474-8.

3 Bolinder J, Hagström E, Ungerstedt U, Arner P. Microdialysis of subcutaneous adipose tissue in vivo for continuous glucose monitoring in man. Scand 7 Clin Lab Invest 1989;49:465-74.
4 Horal M, Ungerstedt U, Persson B, Westgren M, Marcus C. Metabolic adaptation in IUGR neonates with
microdialysis-a pilot study. Early Human Dev 1995;42: microdialy $11-14$.

5 Hildingsson U, Selldén H, Ungerstedt U, Marcus C. Microdialysis for metabolic monitoring in neonates after surgery. Acta Pediatr 1996;85:589-94.

6 Kamel A, Norgren S, Ehrén H, Hildingsson U, Marcus C. Antilipolytic effect of insulin and insulin receptor messenger RNA expression in adipocytes of infants, children and adults. Pediatr Res 1997;41:563-7.

7 Aynsely-Green A. Glucose: a fuel for thought! 7 Paediatr Child Health 1991;27:21-30.

8 Marcus C, Karpe E, Bolme E, Sonnenfeldt T, Arner P. Changes in catecholamine-induced lipolysis in isolated human fat cells during the first year of life. $\mathcal{F}$ Clin Invest 1987;79:1812-18.

9 Engfeldt P, Hellmer J, Wahrenberg H, Arner P. Effects of insulin on adrenoreceptor binding and the rate of catecholamines-induced lipolysis in isolated human fat cells. F Biol Chem 1988;30:15553-60.

10 Bolinder J, Sjöberg S, Arner P. Stimulation of adipose tissue lipolysis following insulin-induced hypoglycemia: evidence lipolysis following insulin-induced hypoglycemia: evidence sponse in IDDM. Diabetologia 1996;39:845-53.

11 Hagström-Toft E, Enoksson S, Moberg E, Bolinder J, Arner $\mathrm{P}$. Absolute concentrations of glycerol and lactate in human skeletal muscle, adipose tissue, and blood. Am $\mathcal{F}$ Physiol 1997;273:E584-92.

12 Pugliese M, Lifshitz F, Fort P, Cervantes C, Recker B, Ginsberg L. Pituitary function assessment in short stature by a combined hormonal stimulation test. Am f Dis Child 1987; 141:556-61.

13 Lövgren T, Hemmilä I, Pettersson K, Halonen P. Timeresolved fluorometry in immunoassays. In: Collins WP, ed. Alternative immunoassays. Chichester: John Wiley \& Sons, Alternative imimit

14 Von Schenck H. Radioimmunoassay of glucagon. In: Larner J, Pohl S, eds. Methods in diabetes research. New York: John Wiley \& Sons, 1984:327-45.

15 Heding LG. Determination of total serum insulin (IRI) in insulin treated diabetic patients. Diabetologia 1972;8:2606.

16 Hjemdahl P, Daleskog M, Kahan T. Determination of plasma catecholamines by high-performance liquid chromatography with electrochemical detection: comparison with a radioenzymatic method. Life Sci 1979;25:131-8.

17 Bahram D, Trinder P. An improved colour reagent for the determination of blood glucose by the oxidase system. Analyst 1972;97:142-5.

18 Foster KJ, Alberti KG, Hinks L, et al. Blood intermediary metabolite and insulin concentrations after an overnight fast: reference ranges for adults and interrelations. Clin Chem 1978;24:1568-72.

19 Bolinder J, Ungerstedt U, Arner P. Microdialysis measurement of the absolute glucose concentration in subcutaneous adipose tissue allowing glucose monitoring in diabetic patients. Diabetologia 1992;35:1177-80.

20 Bolinder J, Hagström-Toft E, Ungerstedt U, Arner P. Self-monitoring of blood glucose in type 1 diabetic patients: comparison with continuos microdialysis measurements of glucose in subcutaneous adipose tissue during ordinary life conditions. Diabetes Care 1997;20:64-70.

21 Felländer G, Nordenström J, Ungerstedt U, Arner P, Bolinder J. Influence of operation on glucose metabolism and lipolysis in human adipose tissue: a microdialysis study. Eur F Surg 1994;160:87-95.

22 Fernqvist-Forbes E, Linde B, Gunnarsson R. Insulin absorption and subcutaneous blood flow in normal subjects during insulin-induced hypoglycemia. $\mathcal{F}$ Clin Endocrinol Metabol 1988;67:619-23.

23 Jansson PAE, Fowelin JP, Von Schenck HP, Smith UP, Lönnroth PN. Measurement by microdialysis of the insulin concentration in subcutaneous interstitial fluid: importance of the endothelial barrier for insulin. Diabetes 1988;42:1469-73.

24 Khan BB, Flier JS. Regulation of glucose transporter gene expression in vitro and in vivo. Diabetes Care 1990;13:548 64 .

25 Nyberg G, Häger A, Smith U. Effect of age on human adipose tissue metabolism and hormonal responsiveness. Acta Paediatr Scand 1977;66:495-500.

26 Glasgow AM. Hypoglycemia of infancy and childhood. In: Becker KL, ed. Principles and practice of endocrinology and metabolism. Philadelphia: JB Lippincott, 1995:1360-8.

27 Morris AAM, Thekekara A, Clayton PT, Leonard JV, Aynsley-Green A. Evaluation of fasts for investigating hypoglycemia or suspected metabolic disease. Arch Dis Child 1996;75:115-19.

28 Marcus C, Sonnenfeld T, Karpe B, Bolme P, Arner P. Inhibition of lipolysis by agents acting via adenylate cyclase in bition of lipolysis by agents acting via adenylate cyclase in

29 Marcus C, Selldén H, Rickardsson E, Lönnqvist PA, Brönnegård $\mathrm{M}$, Arner P. Lack of lipolytic response in infants after endotracheal intubation. Arch Dis Child 1993;68:402-4.

30 Marcus C, Ehren H, Bolme P, Arner P. Regulation of lipolysis during the neonatal period: importance of thyrotropin. $\mathcal{F}$ Clin Invest 1988;82:1793-7. 